\title{
Landmark and outline-based geometric morphometrics analysis of three Stomoxys flies (Diptera: Muscidae)
}

\author{
Tanasak Changbunjong ${ }^{1,2}$, Suchada Sumruayphol ${ }^{3}$, Thekhawet Weluwanarak ${ }^{2}$, Jiraporn Ruangsittichai ${ }^{3}$ and \\ Jean-Pierre Dujardin ${ }^{4}$
}

\author{
${ }^{1}$ Department of Pre-clinic and Applied Animal Science, Faculty of Veterinary Science, Mahidol University, Nakhon Pathom, \\ Thailand; \\ ${ }^{2}$ The Monitoring and Surveillance Center for Zoonotic Diseases in Wildlife and Exotic Animals, Faculty of Veterinary Science, \\ Mahidol University, Nakhon Pathom, Thailand; \\ ${ }^{3}$ Department of Medical Entomology, Faculty of Tropical Medicine, Mahidol University, Bangkok, Thailand; \\ ${ }^{4}$ Institut de Recherches pour le Développement, Campus International de Baillarguet, Montpellier, France
}

\begin{abstract}
Adult flies of the genus Stomoxys Geoffroy, 1762 (Diptera: Muscidae), especially S. pullus Austen, 1909, S. uruma Shinonaga et Kano, 1966 and $S$. indicus Picard, 1908, are morphologically similar and sometimes difficult to distinguish when using external morphological characteristics. These species may act as vectors and/or potential vectors of many pathogens (virus, bacteria and protozoa). Their correct identification is important to target the vectors involved in the transmission of the pathogens and also helps in the fly control program. The aim of the present study was to distinguish three species which are difficult to separate using traditional diagnostic characters for species of Stomoxys such as colour patterns and body proportions. Modern morphometrics, both landmark and outline-based, was used to access wing geometry of S. pullus, S. uruma and S. indicus. A total of 198 and 190 wing pictures were analysed for landmark- and outline-based approaches, respectively. Wing shape was able to separate species and sexes of the three Stomoxys flies with highly significant difference of Mahalanobis distances. The cross-validated classification scores ranged from $76 \%$ to $100 \%$ for landmark and $77 \%$ to $96 \%$ for outline-based morphometrics. The geometry of wing features appears to be a very useful, low-cost tool to distinguish among the vectors S. pullus, S. uruma and S. indicus.
\end{abstract}

Keywords: muscidae, landmarks, outlines, Stomoxys pullus, Stomoxys uruma, Stomoxys indicus

Flies of the genus Stomoxys Geoffroy, 1762 (Diptera: Muscidae) are haematophagous flies of considerable medical and veterinary importance. They are classified into the subfamily Muscinae, tribes Stomoxyini, with 18 species having been described (Zumpt 1973). In Thailand, 6 species of Stomoxys, namely Stomoxys calcitrans (Linnaeus, 1758), S. sitiens Rondani, 1873, S. bengalensis Picard, 1908, S. indicus Picard, 1908, S. pullus Austen, 1909 and S. uruma Shinonaga et Kano, 1966, have been recorded from different geographical areas (Tumrasvin and Shinonaga 1978, Masmeatathip et al. 2006, Muenworn et al. 2010; Changbunjong et al. 2012).

The adult flies feed on the blood of humans and animals, making them a nuisance to humans, a major irritant pest of both livestock and wildlife, and they also act as vectors and potential vectors of many pathogens (Zumpt 1973, Baldacchino et al. 2013). They have been implicated as mechanical vectors of viruses (Equine infectious anemia virus, African swine fever virus, West Nile fever virus and Bo- vine leukosis virus), bacteria (Bacillus anthracis and Anaplasma marginale) and protozoa (species of Trypanosoma Gruby, 1843 and Besnoitia Henry, 1913). Moreover, they also act as biological vectors of the helminth Habronema microstoma Schneider, 1866 (see Baldacchino et al. 2013).

Species identification of adult Stomoxys is based mainly on body colour and pattern, leg colour, frons width proportions, curvature and setation of certain wing veins, occurrence or form of various bristles and hairs on parts of the legs, and also genital structure (Crosskey 1993). Morphological species identification is a gold standard for any taxonomic system, but it might become difficult or unsatisfactory for distinction of cryptic species. Correct identification not only permits critical access to the broad body of literature available on a particular taxon but also permits the implementation of adequate control measures to contend with species of medical and veterinary importance.

Some Stomoxys species such as S. pullus, S. uruma and $S$. indicus have morphological similarity, especially the

Address for correspondence: T. Changbunjong, Department of Pre-clinic and Applied Animal Science, Faculty of Veterinary Science, Mahidol University, Nakhon Pathom 73170, Thailand. Phone: +66-2-4415238; Fax: +66-2-4415238; E-mail: tanasak.cha@mahidol.edu 

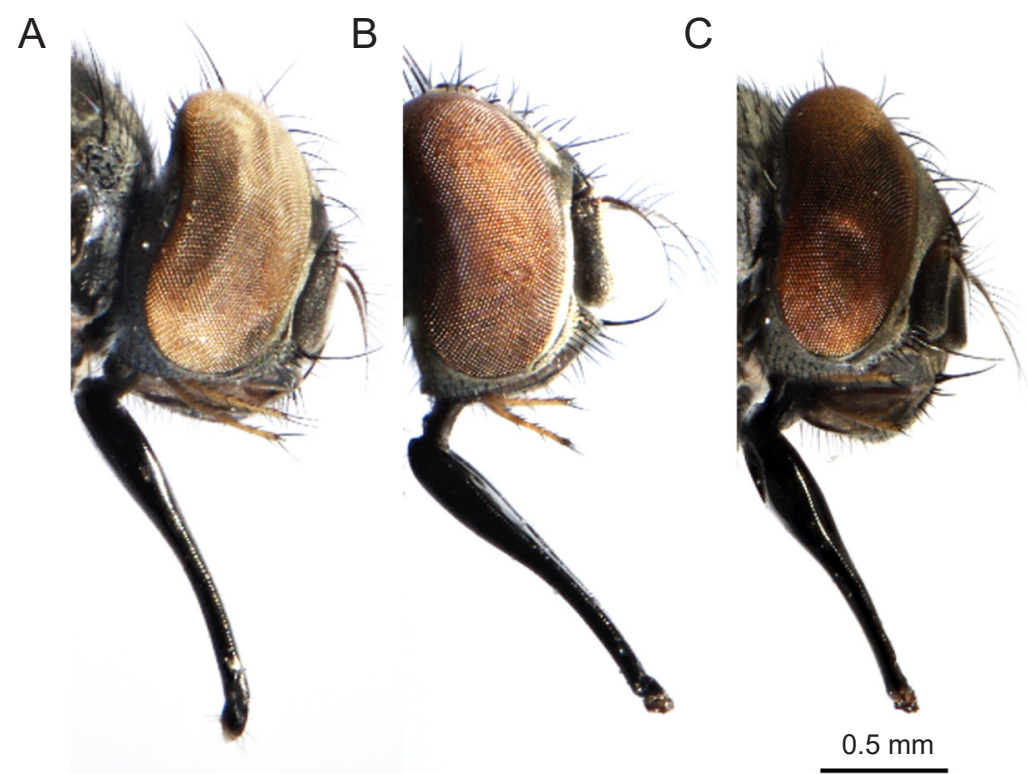

Fig. 1. Morphological characters of palpi used to separate Stomoxys pullus Austen, 1909 (A), S. uruma Shinonaga et Kano, 1966 (B) and S. indicus Picard, 1908 (C).
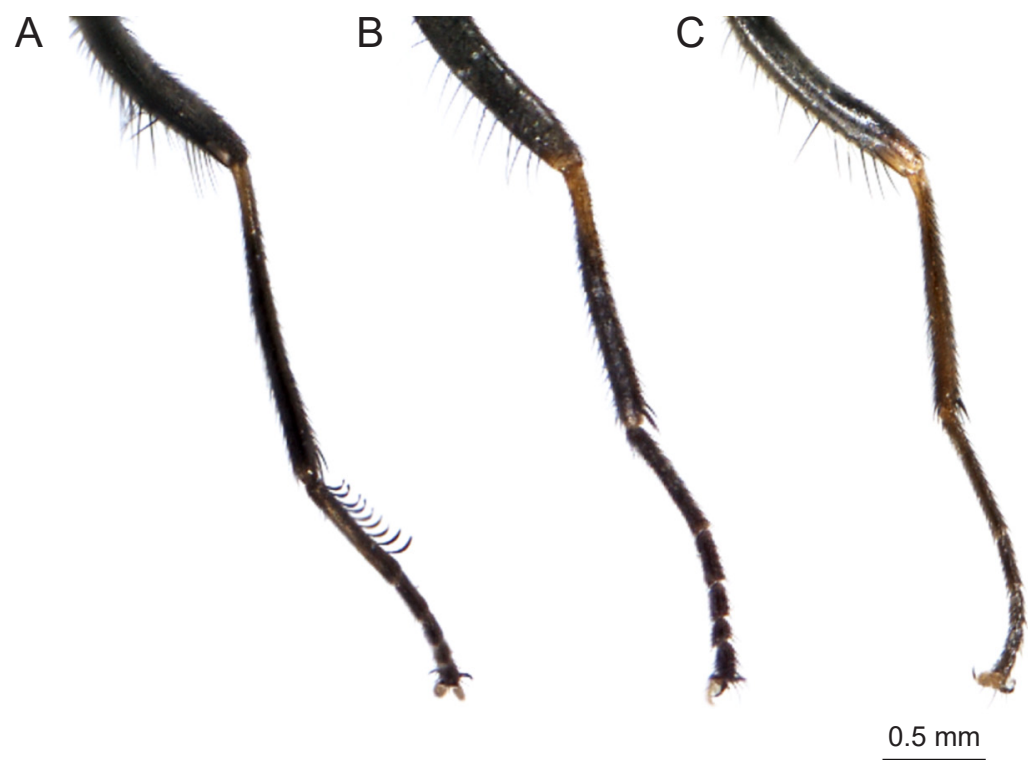

Fig. 2. Morphological characters of tibia and tarsus used to separate Stomoxys pullus Austen, 1909 (A), S. uruma Shinonaga et Kano, 1966 (B) and S. indicus Picard, 1908 (C).

body colour and abdominal pattern (Zumpt 1973), and the body size, as well as the frontal index (the ratio of the smallest width of the frons and the greatest length of the eye), cannot clearly separate them (Changbunjong et al. 2013). As an additional difficulty, these species can also be found in the same areas (Changbunjong et al. 2012).

According to Tumrasvin and Shinonaga (1978), S. pullus can be distinguished from S. uruma and S. indicus by the length of maxillary palpi exceeding the fore margin of the mouth and the different colour at the basal part of the third antennal segment. Stomoxys indicus can be distinguished from $S$. uruma by the yellowish colour of tibiae and tarsi (Figs. 1,2). These morphological traits may be used as the primary method for screening specimens in the field, or for identifying uncomplicated specimens. Howev- er, the morphological-based identification of these flies is often impeded by polymorphism, overlapping morphological characteristics and damage caused to specimens during collection.

Molecular-based identification can resolve various problems encountered during morphology-based identification, especially of morphologically close species (Hebert 2003a,b), but its use is expensive and requires specialised training (Müller et al. 2013). Geometric morphometrics is increasingly applied to medically and economically important insects to distinguish morphologically similar species, especially cryptic taxa, and to detect intraspecific variation (Dujardin 2008, Ruangsittichai et al. 2011, Lorenz et al. 2012, Dujardin and Kitthawee 2013, Morales Vargas et al. 2013, Demari-Silva et al. 2014, Jaramillo-O et al. 2015, 
Table 1. Number of flies of species Stomoxys Geoffroy, 1762 used for geometric morphometrics analysis.

\begin{tabular}{lcc}
\hline \multirow{2}{*}{ Species (sex) } & \multicolumn{2}{c}{ Number } \\
\cline { 2 - 3 } & $\begin{array}{c}\text { Landmark- } \\
\text { based method }\end{array}$ & $\begin{array}{c}\text { Outline-based } \\
\text { method }\end{array}$ \\
\hline S. pullus Austen, 1909 (male) & 35 & 34 \\
S. pullus (female) & 35 & 33 \\
S. uruma Shinonaga et Kano, 1966 (male) & 34 & 32 \\
S. uruma (female) & 34 & 31 \\
S. indicus Picard, 1908 (male) & 30 & 30 \\
S. indicus (female) & 30 & 30 \\
\hline Total & 198 & 190 \\
\hline
\end{tabular}

Table 2. Description of landmarks on wings of species of Stomoxys Geoffroy, 1762 (see Fig. 3).

\begin{tabular}{cl}
\hline Landmark & Description of the landmark \\
\hline 1 & medial vein 3 and cubital vein 1 \\
2 & medial cross vein \\
3 & midpoint branch of medial vein \\
4 & radio-medial cross vein \\
5 & distal end of medial vein 1 and 2 \\
6 & distal end of the radial vein 4 and 5 \\
7 & distal end of the radial vein 2 and 3 \\
8 & origin of radial vein 2 and 3 \\
9 & intersection of costa and radial vein 1 \\
10 & intersection of costa and subcosta \\
\hline
\end{tabular}

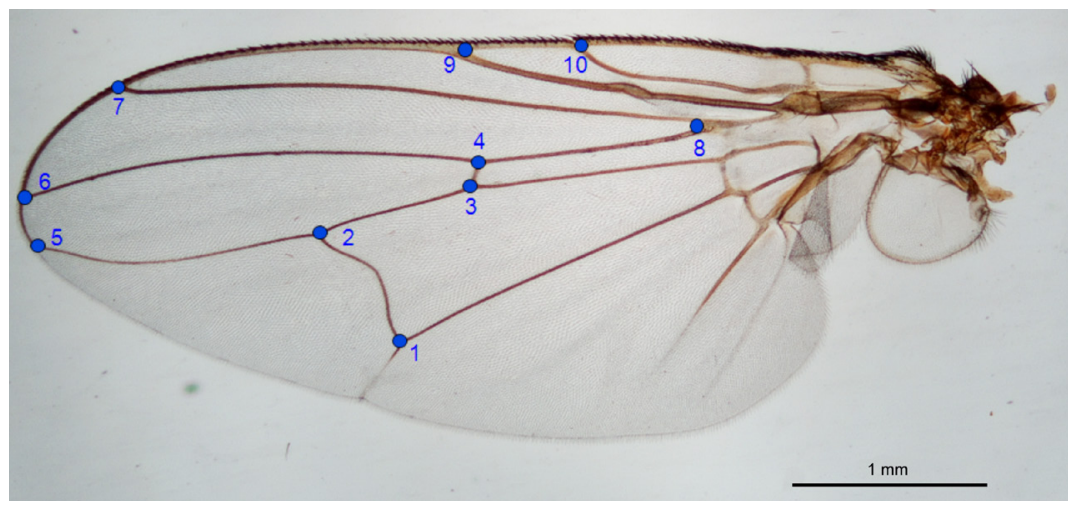

Fig. 3. Ten landmarks digitised on wings of species of Stomoxys Geoffroy, 1762 flies for landmark-based geometric morphometrics analysis (see Table 2 for description).

Sumruayphol et al. 2016). Wing veins provide many well-defined landmarks suitable for the landmark-based approach (Villegas et al. 2002). In addition to landmark-based morphometrics, outline-based morphometrics has been shown to be a reliable method for characterising various wingless insects and some arthropods (other than insects) with poorly defined landmarks (Dujardin et al. 2014).

A recent study has shown the efficacy of outline-based morphometrics for discriminating between closely related species, or between conspecific populations, of various arthropods including kissing bugs, tsetse flies, mosquito and soft ticks (Dujardin et al. 2014). The combined use of landmarks and outlines could represent a better method for discrimination between species (Francoy et al. 2012). Although geometric morphometrics does not reach the level of molecular accuracy, the present findings show that it can be highly and quickly informative at low cost. In the present study, we used landmark and outline-based geometric morphometrics to identify vector species of the genus Stomoxys focusing on three closely related species in Thailand.

\section{MATERIALS AND METHODS}

\section{Specimen collection}

Flies were collected between July 2014 and August 2015 in two localities in western and northeastern Thailand: S. pullus and S. uruma from Nakhon Ratchasima Province $\left(14^{\circ} 24^{\prime} 55^{\prime \prime N}\right.$; $\left.101^{\circ} 22^{\prime} 33^{\prime \prime E}\right)$ and $S$. indicus from Kanchanaburi Province $\left(14^{\circ} 25^{\prime} 54^{\prime \prime} \mathrm{N}\right.$; $\left.98^{\circ} 48^{\prime} 35^{\prime \prime} \mathrm{E}\right)$ using Vavoua traps (Laveissière and Grebaut 1990). The traps were placed at the collection sites from 6:00 AM to 6:00 PM over a two-day-period (Changbunjong et al. 2012). Species were identified with a stereomicroscope based on the taxonomic key of Zumpt (1973) and Tumrasvin and Shinonaga (1978).

\section{Sample preparation and data collection}

The left wings of males and females belonging to $S$. pullus, $S$. uruma and $S$. indicus were dissected from the body and mounted by Hoyer's medium on microscopic slides. The wings were placed at the center of the visual view to avoid peripheral optical distortion. All slides were photographed using a digital camera connected to a stereomicroscope (Nikon AZ 100, Nikon Corp, Tokyo, Japan) at 10× magnification. A total of 198 and 190 wing pictures of the three species of Stomoxys flies were performed for landmark and outline-based methods, respectively. The simple external contour of the wings was used for outlines, but in eight wings the contours were damaged and so were not satisfactory for outline analysis. Otherwise, the same set of wing pictures was used to compare both methods (Table 1).

\section{Geometric morphometrics analysis}

\section{Landmark-based method}

The coordinates of ten wing landmarks (Table 2 and Fig. 3) were selected and digitised for geometric morphometrics analysis. The wing size was estimated using the isometric estimator of 


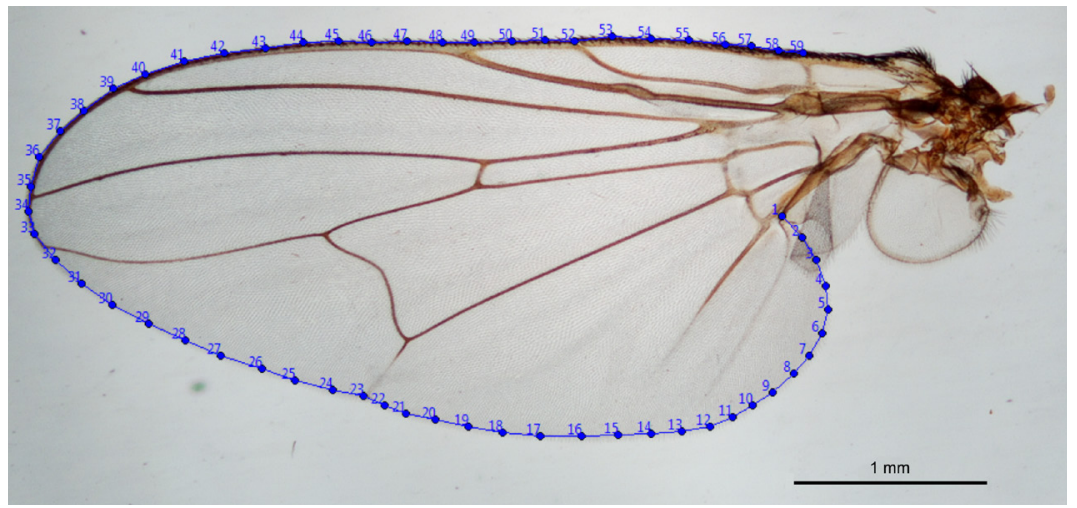

Fig. 4. Contour digitised on Stomoxys Geoffroy, 1762 flies wing for outline-based geometric morphometrics analysis. A short, artificial segment is computed by the digitising program to completely close the contour.

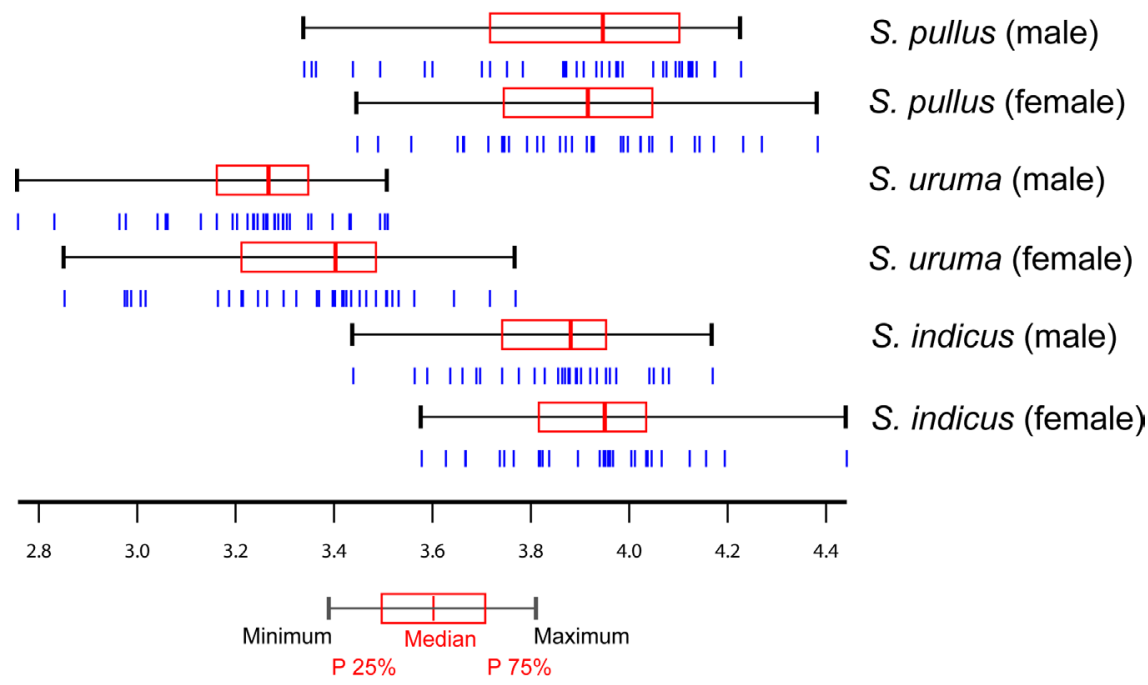

Fig. 5. Centroid size variation of the wings between species and sexes, shown as quartile boxes. Each box shows the group median separating the $25^{\text {th }}$ and $75^{\text {th }}$ quartiles. Vertical bars under the boxes represent the wing (units as $\mathrm{mm}$ ).

the centroid size $(\mathrm{CS})$ derived from data on coordinates. The centroid size is defined as the square root of the sum of the squared distances between the centre of the configuration of landmarks and each separate landmark (Bookstein 1991). The centroid size difference was compared among species and sexes (15 pairwise comparisons) by non-parametric tests based on 1000 permutations, with Bonferroni correction for test of significance at $P$-value of 0.05 .

Generalised Procrustes Analysis (GPA) (Rohlf 1990) was performed to compute the wing shape variables and the centroid sizes. The Procrustes superimposition provided configurations for visual comparisons of the mean anatomical landmarks between species and sexes. The wing shape variables were initially computed from these configurations ('aligned' configurations) as the partial warps (PW) scores. Then their principal components or relative warps (RW) were used as input for the discriminant analyses (or canonical variate analysis). The discriminant analyses were illustrated by the factor maps. The statistical significance of shape differences among the species and sexes was obtained by non-parametric analyses based on 1000 permutations, with Bonferroni correction for test of significance at $P$-value of 0.05 .

\section{Outline-based method}

The outline considered for species comparisons was the external contour of the wing (Fig. 4). The wing size may be estimated as the outline perimeter or by the square root of the first harmonic ellipse area, It was compared among species and sexes using non-parametric analyses in the same way as for CS.

Elliptic Fourier Analysis (EFA) (Kuhl and Giardina 1982) was performed to produce the wing shape variables. It provided configurations for visual comparisons of the outlines between species and sexes. The wing shape variables were computed as Normalised Elliptic Fourier coefficients. To deal with possible problems of multidimensionality, a reduced set of their principal components was used as input for the discriminant analyses (for methodological details, see Dujardin et al. 2014). Statistical comparisons of wing shape among the species and sexes were the same as those used for the landmark-based method.

\section{Validate classification}

To test the accuracy of species classification yielded by geometric morphometrics, the Mahalanobis distances were used to perform a cross-validated classification (or jackknife classifica- 
Table 3. $P$-values of mean centroid size differences among populations of Stomoxys pullus Austen, 1909, S. uruma Shinonaga et Kano, 1966 and S. indicus Picard, 1908.

\begin{tabular}{|c|c|c|c|c|c|}
\hline Species (sex) & $\begin{array}{l}\text { S. pullus } \\
\text { (m) }\end{array}$ & $\begin{array}{l}\text { S. pullus } \\
\text { (f) }\end{array}$ & $\begin{array}{l}\text { S. uruma } \\
(\mathrm{m})\end{array}$ & $\begin{array}{l}\text { S. uruma } S \\
\text { (f) }\end{array}$ & $\begin{array}{l}\text { S. indicusS. indicus } \\
\text { (m) }\end{array}$ \\
\hline \multicolumn{6}{|l|}{ S. pullus (m) } \\
\hline S. pullus (f) & NS & & & & \\
\hline S. uruma $(\mathrm{m})$ & $\mathrm{S}$ & $\mathrm{S}$ & & & \\
\hline S. uruma (f) & $\mathrm{S}$ & $\mathrm{S}$ & NS & & \\
\hline S. indicus $(\mathrm{m})$ & NS & NS & $\mathrm{S}$ & $\mathrm{S}$ & \\
\hline S. indicus (f) & NS & NS & $\mathrm{S}$ & $\mathrm{S}$ & NS \\
\hline
\end{tabular}

The level of statistic significance was first computed from a non-parametric test, then corrected after Bonferroni test (see Materials and Methods). $\mathrm{m}$ - male; $\mathrm{f}$ - female; $\mathrm{S}$ - significant $(\mathrm{P}<0.05)$; NS - not significant $(\mathrm{P}>0.05)$.

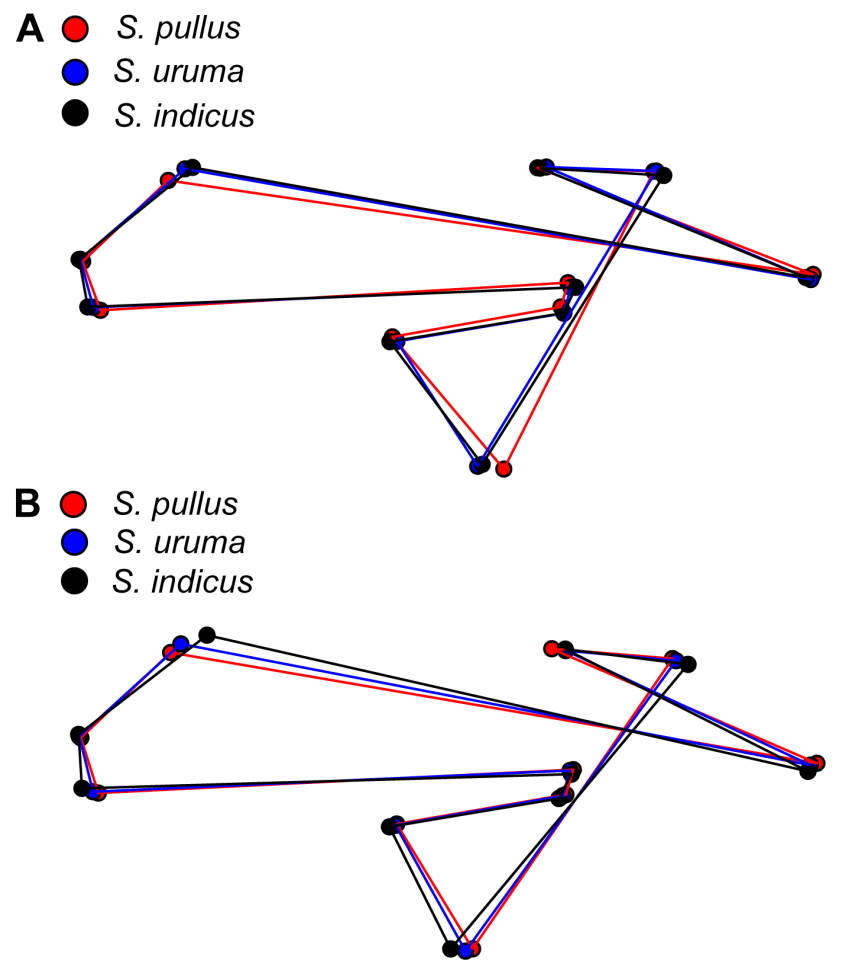

Fig. 6. Configurations of the ten anatomical landmarks connected by a straight line after procrustes superimposition of three species of Stomoxys Geoffroy, 1762, in males (A) and females (B).

Table 4. Landmark-based Mahalanobis distances between wing shapes of Stomoxys pullus Austen, 1909, S. uruma Shinonaga et Kano, 1966 and S. indicus Picard, 1908.

\begin{tabular}{|c|c|c|c|c|c|c|}
\hline Species (sex) & $\begin{array}{l}\text { S. pullus } \\
\text { (m) }\end{array}$ & $\begin{array}{l}\text { S. pullus } \\
\text { (f) }\end{array}$ & $\begin{array}{l}\text { S. uruma } \\
(\mathrm{m})\end{array}$ & $\begin{array}{l}\text { S. urumas } \\
\text { (f) }\end{array}$ & $\begin{array}{l}\text { S. indicus } \\
(\mathrm{m})\end{array}$ & $\begin{array}{l}\text { S. indicus } \\
\text { (f) }\end{array}$ \\
\hline S. pullus (m) & 0.00 & & & & & \\
\hline S. pullus (f) & 6.68 & 0.00 & & & & \\
\hline S. uruma (m) & 5.64 & 5.06 & 0.00 & & & \\
\hline S. uruma (f) & 8.06 & 3.23 & 5.05 & 0.00 & & \\
\hline S. indicus $(\mathrm{m})$ & 8.04 & 7.94 & 5.54 & 7.43 & 0.00 & \\
\hline S. indicus (f) & 12.83 & 9.38 & 8.81 & 7.54 & 6.76 & 0.00 \\
\hline
\end{tabular}

The level of statistic significance was first computed from a non-parametric test, then corrected after Bonferroni test (see Materials and Methods) Mahalanobis distances were highly significant for all pairwise comparisons. $\mathrm{m}$ - male; $\mathrm{f}$ - female. tion), in which each individual is allocated to its closest group without being used to help determine a group centre (Manly 2004).

\section{Software}

Collections of anatomical landmarks, data analyses and graphical outputs were performed using the various modules of CLIC package version 97 (Dujardin et al. 2010); the Collection of Coordinates (COO) module for collecting landmarks and outlines; the Tabla, Espacios, Texto (TET) module for modifying the data; the Morformetria Geometrica (MOG) module for GPA analyses and generation of CS, PW and RW; the Fourier Outlines Graphics (FOG) module for EFA analyses; the Variation and variance (VAR) module for size analysis and the Permutaciones Analisis Discriminante (PAD) module for shape analysis.

\section{RESULTS}

\section{Landmark-based geometric morphometrics}

The largest wing (centroid size) was found in female Stomoxys indicus $(3.88 \mathrm{~mm})$, whereas the smallest wing was found in male $S$. uruma (3.22 $\mathrm{mm})$. The remaining populations had following wing size: $3.87 \mathrm{~mm}$ (female $S$. pullus), $3.85 \mathrm{~mm}$ (male $S$. pullus), $3.82 \mathrm{~mm}$ (male $S$. indicus) and $3.32 \mathrm{~mm}$ (female $S$. uruma). The size relationships among samples is illustrated in Fig. 5, and their statistical significance is shown in Table 3.

The visual comparisons of the mean anatomical landmark positions between species and sexes showed most visible landmarks displacements in the upper and lower part of wing (landmarks 1, 7, 9, 10) (Fig. 6). Based on the Mahalanobis distances comparisons, the wing shape was significantly different among species and sexes of the three species of Stomoxys (Table 4). The discriminant analysis for the wing landmark-based shape showed that individuals clustered into distinct groups in males, whereas females of S. pullus and S. uruma showed some overlapping (Fig. 7). The accuracy scores after cross-validated classification test ranged from $76 \%$ to $100 \%$, showing better values in males (Table 5).

\section{Outline-based geometric morphometrics}

For outline-based method, the largest wing (perimeter) was found in male $S$. pullus $(10.95 \mathrm{~mm})$, whereas the smallest wing was found in both male and female $S$. uruma $(9.12 \mathrm{~mm})$. The remaining populations had the following wing size: $10.92 \mathrm{~mm}$ (male $S$. indicus), $10.84 \mathrm{~mm}$ (female S. indicus) and $10.52 \mathrm{~mm}$ (female $S$. pullus). The size relationships among samples is illustrated in Fig. 8, and their statistical significance is shown in Table 6.

The visual comparisons of contours between species and sexes are shown in Fig 9. Subtle differences of contours were observed in the males of all three species, and female of S. pullus and S. uruma. Based on the Mahalanobis distances comparisons, the wing outline-based shape variables were significantly different among species and sexes of all taxa studied (Table 7). In both sexes, the factor map 

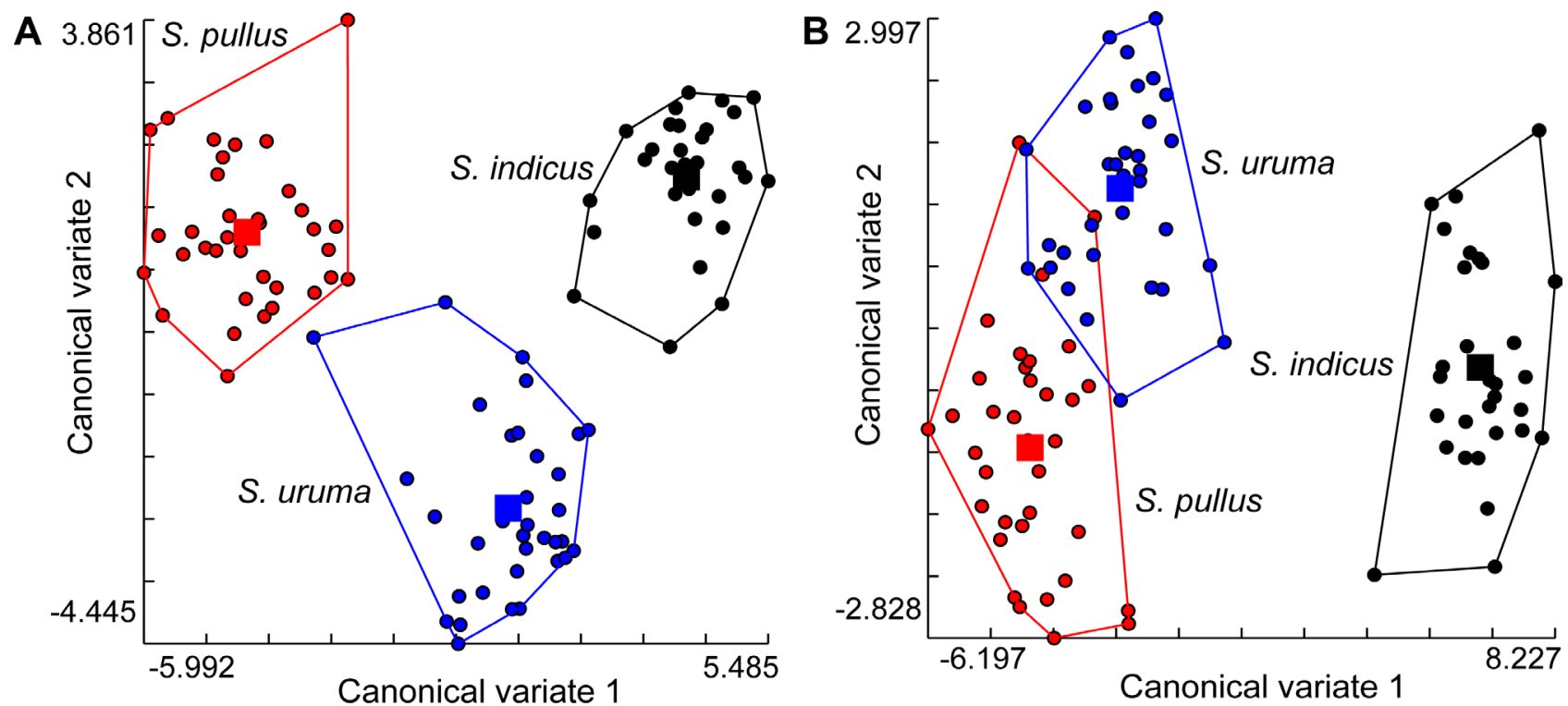

Fig. 7. Landmark-based discriminant analysis. Factor map of canonical variates resulting from comparison among the three species of Stomoxys Geoffroy, 1762, in males (A) and females (B).

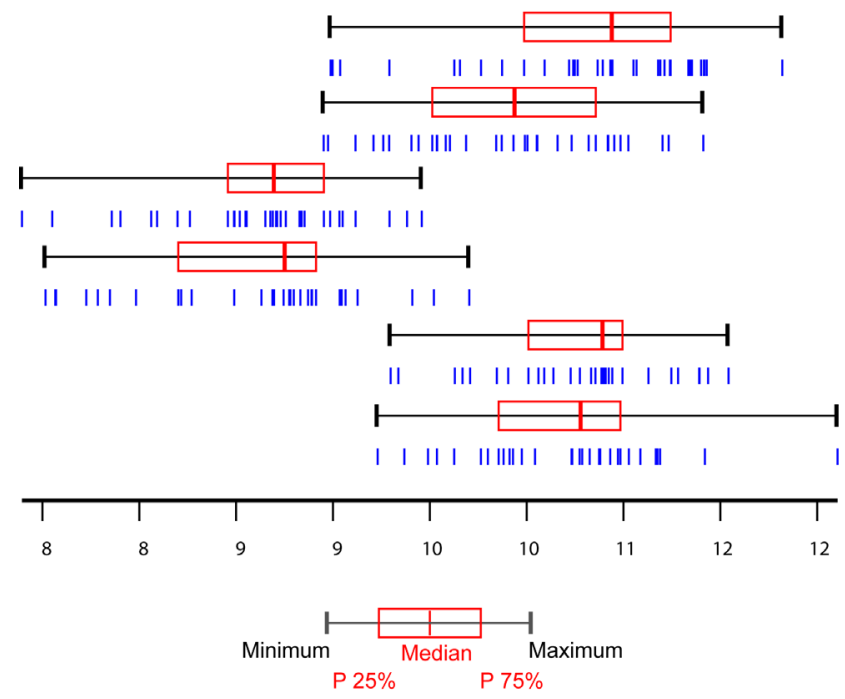

S. pullus (male)

S. pullus (female)

S. uruma (male)

S. uruma (female)

S. indicus (male)

S. indicus (female)

Fig. 8. Perimeter variation of the wings between species and sexes, shown as quartile boxes. Each box shows the group median separating the $25^{\text {th }}$ and $75^{\text {th }}$ quartiles. Vertical bars under the boxes represent the wing (units as $\mathrm{mm}$ ).

Table 5. Cross-validated classification of Stomoxys pullus Austen, 1909, S. uruma Shinonaga et Kano, 1966 and S. indicus Picard, 1908 based on the shape of the wings.

\begin{tabular}{lcccc}
\hline \multirow{2}{*}{ Species } & \multicolumn{2}{c}{ Landmark-based } & \multicolumn{2}{c}{ Outline-based } \\
\cline { 2 - 5 } & Male & Female & Male & Female \\
\hline S. pullus & $97 \%(34 / 35)$ & $91 \%(32 / 35)$ & $91 \%(31 / 34)$ & $81 \%(27 / 33)$ \\
S. uruma & $97 \%(33 / 34)$ & $76 \%(26 / 34)$ & $84 \%(27 / 32)$ & $77 \%(24 / 31)$ \\
S. indicus & $100 \%(30 / 30)$ & $96 \%(29 / 30)$ & $86 \%(26 / 30)$ & $96 \%(29 / 30)$ \\
\hline
\end{tabular}

Table 6. $P$-values of mean perimeter differences among populations of Stomoxys pullus Austen, 1909, S. uruma Shinonaga et Kano, 1966 and S. indicus Picard, 1908.

\begin{tabular}{|c|c|c|c|c|c|}
\hline Species (sex) & $\begin{array}{l}\text { S. pullus } \\
\text { (m) }\end{array}$ & $\begin{array}{l}\text { S. pullus } \\
\text { (f) }\end{array}$ & $\begin{array}{l}\text { S. uruma } \\
\text { (m) }\end{array}$ & $\begin{array}{l}\text { S. uruma } \\
\text { (f) }\end{array}$ & $\begin{array}{l}\text { S. indicus S. indicu } \\
\begin{array}{l}\text { (m) } \\
\text { (f) }\end{array}\end{array}$ \\
\hline \multicolumn{6}{|l|}{ S. pullus $(\mathrm{m})$} \\
\hline S. pullus (f) & NS & & & & \\
\hline S. uruma $(\mathrm{m})$ & $\mathrm{S}$ & $\mathrm{S}$ & & & \\
\hline S. uruma (f) & $\mathrm{S}$ & $\mathrm{S}$ & NS & & \\
\hline S. indicus (m) & NS & NS & $\mathrm{S}$ & $\mathrm{S}$ & \\
\hline S. indicus (f) & NS & NS & $\mathrm{S}$ & $\mathrm{S}$ & NS \\
\hline
\end{tabular}

The level of statistic significance was first computed from a non-parametric test, then corrected after Bonferroni test (see Materials and Methods) $\mathrm{m}$ - male; $\mathrm{f}$ - female; $\mathrm{S}$ - significant $(\mathrm{P}<0.05)$; NS - not significant $(\mathrm{P}>0.05)$. 

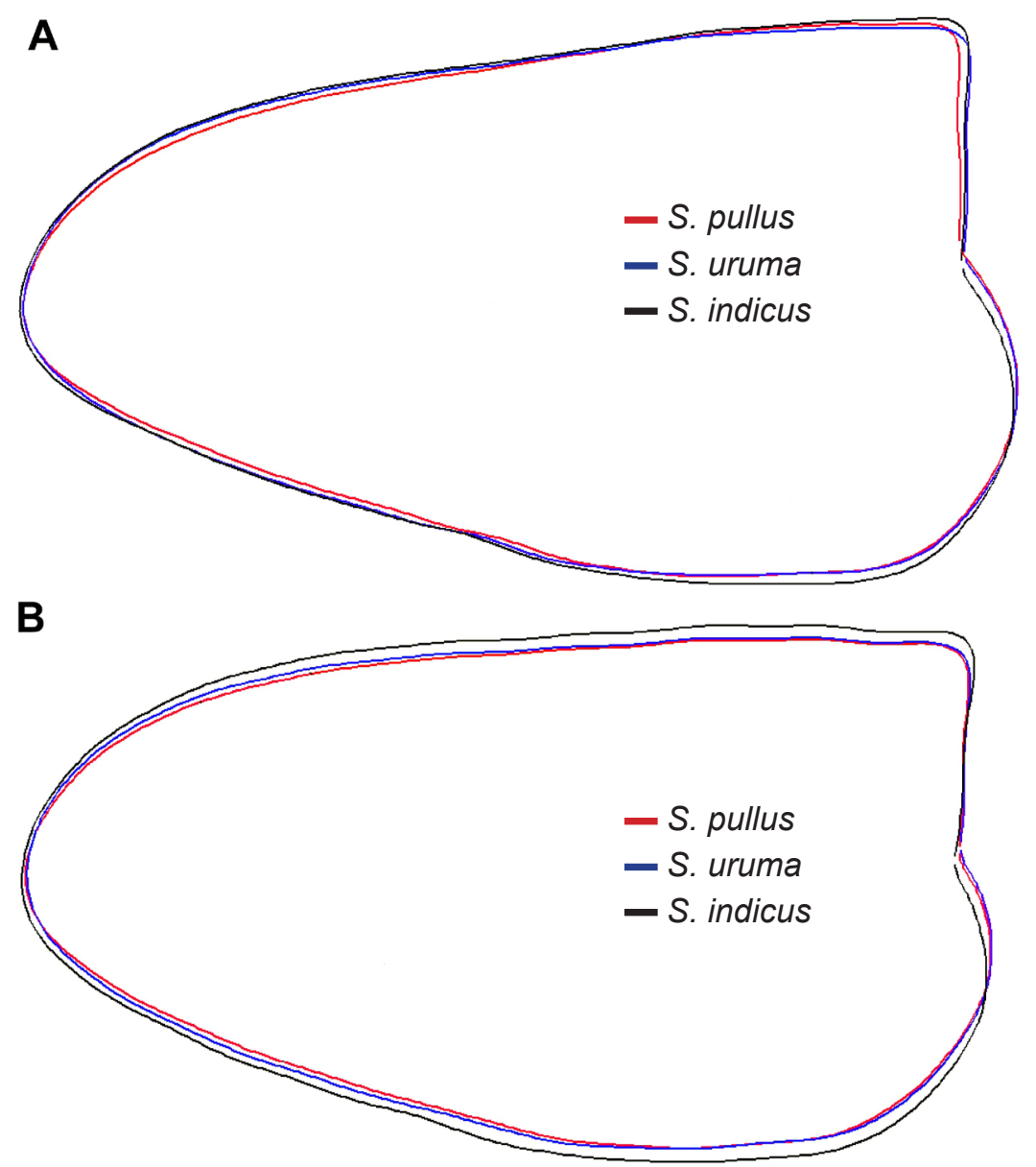

Fig. 9. Configurations of the outlines after Elliptic Fourier Analysis of Stomoxys pullus Austen, 1909, S. uruma Shinonaga et Kano, 1966 and S. indicus Picard, 1908, in males (A) and females (B). Areas outlined by different colours represent shape, not size.

Table 7. Outline-based Mahalanobis distance between outlines of Stomoxys pullus Austen, 1909, S. uruma Shinonaga et Kano, 1966 and S. indicus Picard, 1908.

\begin{tabular}{|c|c|c|c|c|c|c|}
\hline Species (sex) & $\begin{array}{l}\text { S. pullus } \\
(\mathrm{m})\end{array}$ & $\begin{array}{l}\text { S. pullus } \\
\text { (f) }\end{array}$ & $\begin{array}{l}\text { S. uruma } \\
(\mathrm{m})\end{array}$ & $\begin{array}{l}\text { S. uruma } S \text {. } \\
\text { (f) }\end{array}$ & $\begin{array}{l}\text { indicus } S \text {. } \\
(\mathrm{m})\end{array}$ & $\begin{array}{l}\text { S. indicus } \\
\text { (f) }\end{array}$ \\
\hline S. pullus (m) & 0.00 & & & & & \\
\hline S. pullus (f) & 9.14 & 0.00 & & & & \\
\hline S. uruma $(\mathrm{m})$ & 4.73 & 7.62 & 0.00 & & & \\
\hline S. uruma (f) & 9.76 & 2.66 & 7.56 & 0.00 & & \\
\hline S. indicus $(\mathrm{m})$ & 6.30 & 8.44 & 4.55 & 8.62 & 0.00 & \\
\hline S. indicus (f) & 11.13 & 6.31 & 9.20 & 6.01 & 8.80 & 0.00 \\
\hline
\end{tabular}

The level of statistic significance was first computed from a non-parametric test, then corrected after Bonferroni test (see Materials and Methods). Mahalanobis distances were highly significant for all pairwise comparisons. $\mathrm{m}-$ male; $\mathrm{f}-$ female.

derived from the discriminant analysis for the wing shape showed slightly overlapping areas between S. pullus and S. uruma (Fig. 10). The accuracy scores after cross-validated classification test ranged from $77 \%$ to $96 \%$ (Table 5).

\section{DISCUSSION}

This research provides new information about the morphology of Stomoxys flies. Some species of Stomox$y s$, especially the females of $S$. pullus and $S$. uruma, are very similar and difficult to identify using taxonomic key (Changbunjong et al. 2013). Hence, accurate species identi- fication of these flies is an important pre-requisite to help in fly control program (Bhakdeenuan et al. 2012). Our results revealed that both landmark and outline-based geometric morphometrics of the wings can distinguish the three species of Stomoxys (S. pullus, S. uruma and S. indicus).

The comparison of the wing size by using average centroid size or perimeter of the wing contour showed that the wing size of $S$. indicus and $S$. pullus was not significantly different, but consistently larger than of $S$. uruma. Our results indicated that wing size could help in distinguishing $S$. pullus from S. uruma, or S. indicus from S. uruma. However, wing size can have a major affect from environmental factors such as temperature, relative humidity and food availability (Jirakanjanakit et al. 2007, Morales-Vargas et al. 2010, Ayala et al. 2011). Moreover, S. indicus were collected in our study from different sites and seasons compared to S. pullus and S. uruma that may also have had an affect on wing size (Schachter-Broide et al. 2009, Prudhomme et al. 2012). These environmental factors can influence wing size variable much more than wing shape which often depends on genetic drift and evolutionary divergence (Dujardin 2008, Klingenberg 2010).

The discriminant analysis of landmark and outline-based methods showed that both sexes of $S$. indicus are well separated from $S$. pullus and S. uruma. This finding parallels previous results indicating that $S$. indicus can 

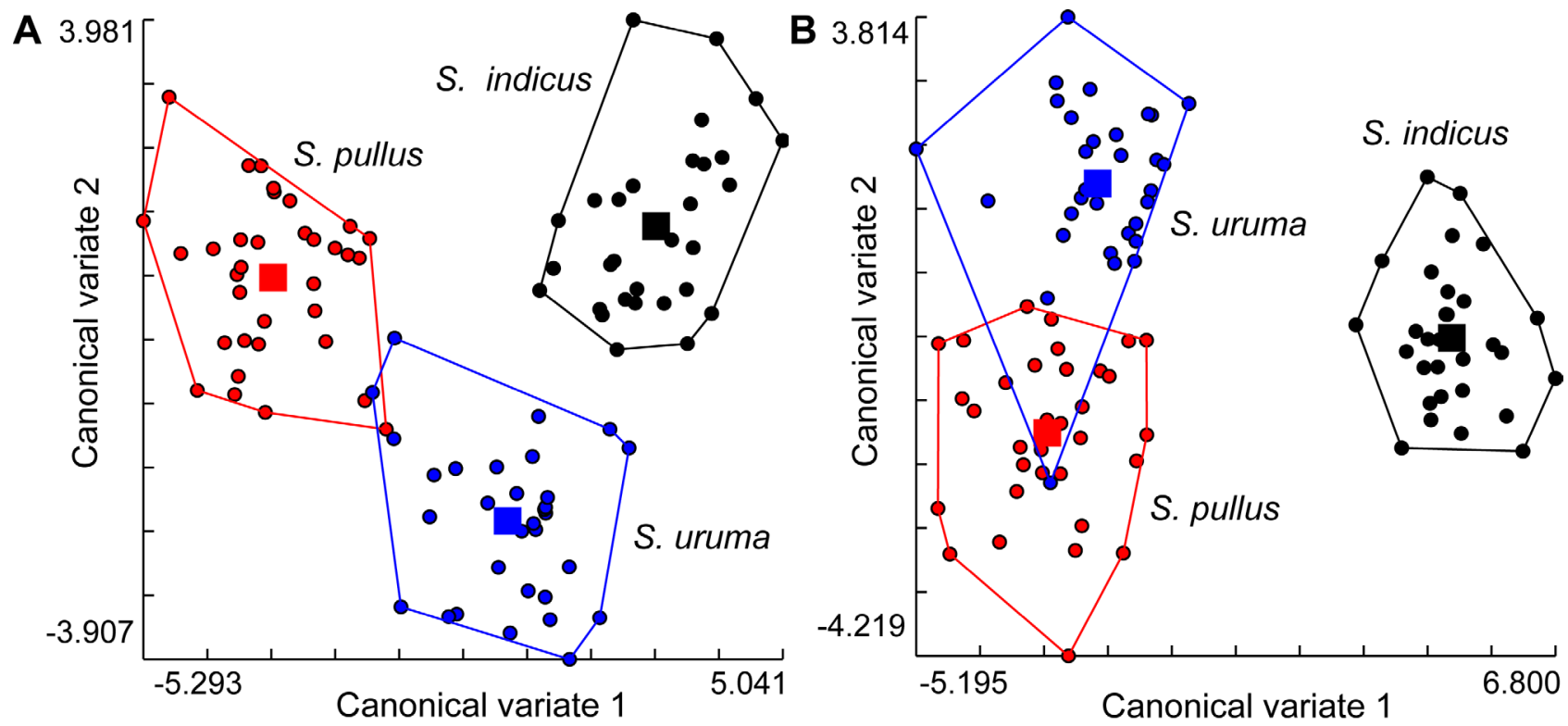

Fig. 10. Outline-based discriminant analysis. Factor map of canonical variates (i.e. discriminant factors) derived from the principal components of the Normalised Elliptic Fourier coefficients of three species of Stomoxys Geoffroy, 1762, in males (A) and females (B).

be distinguished by the adult external morphology (yellowish colour of tibiae and tarsi) (Tumrasvin and Shinonaga 1978). Additionally, the phylogenetic relationship based on cytochrome c oxidase subunit I (COI) showed that S. pullus and S. uruma have a closer genetic relationship than either has with $S$. indicus (T.C. - unpubl. data). They were occasionally misidentified, especially in the females as observed after cross-validated reclassification. Males of $S$. pullus and S. uruma were, however, quite clearly distinguished, especially by landmark analyses. The reclassification scores based on landmark analyses (76\% to $100 \%)$ and outline analyses (77\% to $96 \%)$ were quite similar. These results corresponded to those of the previous study of Dujardin et al. (2014). These authors showed that an outline-based approach could produce similar or even better discrimination scores than landmarks for various arthropods including kissing bugs, tsetse flies, mosquito and soft ticks (Dujardin et al. 2014).

In conclusion, the landmark and outline-based geometric morphometrics of the wings proved to be a very useful tool to help in the morphological distinction of the vectors S. pullus, S. uruma and S. indicus. They have the potential to improve the vector surveillance, hence the planning of fly control programs.

Acknowledgements. This research is supported by Mahidol University. We would like to thank the Department of National Parks, Wildlife and Plant Conservation for permission to conduct the study in the area.

\section{REFERENCES}

Ayala D., Caro-Riaño H., Dujardin J.P., Rahola N., Simard F., Fontenille D. 2011: Chromosomal and environmental determinants of morphometric variation in natural populations of the malaria vector Anopheles funestus in Cameroon. Infect. Genet. Evol. 11: 940-947.

Baldacchino F., Muenworn, V., Desquesnes M., Desol F., Charoenviriyaphap T., Duvallet G. 2013: Transmission of pathogens by Stomoxys flies (Diptera: Muscidae). A review. Parasite 20: 26.

Bhakdeenuan P., Siriyasatien P., Payungporn S., Preativatanyou K., Thavara U., Tawatsin A. 2012: Molecular analysis of medically and veterinary important muscid flies (Diptera: Muscidae) in Thailand. Thai J. Vet. Med. 42: 333-342.

Bookstein F.L. (Ed.) 1991: Morphometric Tools for Landmark Data: Geometry and Biology. Cambridge University Press, New York, $435 \mathrm{pp}$.

Changbunjong T., Weluwanarak T., Ratanakorn P., Maneeon P., Apiwathnasorn C., Sungvornyothin S., SRIWichai P., Sumruayphol S., Ruangsittichai J. 2012: Distribution and abundance of Stomoxyini flies (Diptera: Mus- cidae) in Thailand. Southeast Asian J. Trop. Med. Publ. Hlth. 46: 1400-1410.

Changbunjong T., Weluwanarak T., Sedwisai P., Chamsai T. 2013: Stomoxyini fly fauna of the Khao Yai National Park, Thailand. Asian Pac. J. Trop. Dis. 3: 348-351.

Crosskey R.W. 1993: Stable flies and horn flies (bloodsucking Muscidae). In: R.P. Lane and R.W. Crosskey (Eds), Medical Insects and Arachnids. Chapman \& Hall, London, pp. 389-400.

Demari-Silva B., Suesdek L., Sallum M.A., Marrelli M.T. 2014: Wing geometry of Culex coronator (Diptera: Culicidae) from South and Southeast Brazil. Parasit. Vectors 7: 174.

DUJARDIN J.P. 2008: Morphometrics applied to medical entomology. Infect. Genet. Evol. 8: 875-890.

Dujardin J.P., Kaba D., Henry A.B. 2010: The exchangeability of shape. BMC Res. Notes 3: 266.

Dujardin J.P., Kaba D., Solano P., Dupraz M., McCoy K.D., JARAMILLO-O N. 2014: Outline-based morphometrics, an overlooked method in arthropod studies? Infect. Genet. Evol. 28: 704-714

Dujardin J.P., Kitthawee S. 2013: Phenetic structure of two Bactrocera tau cryptic species (Diptera: Tephritidae) infesting 
Momordica cochinchinensis (Cucurbitaceae) in Thailand and Laos. Zoology (Jena) 116: 129-138.

Francoy T.M., Franco F.F., Roubik D.W. 2012: Integrated landmark and outline-based morphometric methods efficiently distinguish species of Euglossa (Hymenoptera, Apidae, Euglossini). Apidologie 43: 609-617.

Hebert P.D.N., Cywinska A., Ball S.L., de WaArd J.R. 2003a: Biological identifications through DNA barcodes. Proc. Biol. Sci. 270: 313-321.

Hebert P.D.N., Ratnasingham S., deWaard J.R. 2003b: Barcoding animal life: cytochrome $\mathrm{c}$ oxidase subunit 1 divergences among closely related species. Proc. Biol. Sci. 270: S96-99.

Jaramillo-O N., Dujardin J.P., Calle-Londoño D., FonseCA-GonzÁLEZ I. 2015: Geometric morphometrics for the taxonomy of 11 species of Anopheles (Nyssorhynchus) mosquitoes. Med. Vet. Entomol. 29: 26-36.

Jirakanjanakit N.L.S., Thongrungkiat S., Apiwathnasorn C., Singhaniyom S., Bellec C., Dujardin J.P. 2007: Influence of larval density or food variation on the geometry of the wing of Aedes (Stegomyia) aegypti. Trop. Med. Int. Hlth 12: 1354-1360.

KLINGENBERG C.P. 2010: Evolution and development of shape: integrating quantitative approaches. Nat. Rev. Genet. 11: 623-635.

Kuhl F.P., Giardina C.R. 1982: Elliptic Fourier features of a closed contour. Comput. Graph. Image Process 18: 236-258.

Laveissière C., Grebaut P. 1990: The trapping of tsetse flies (Diptera: Glossinidae) improvement of a model: the Vavoua trap. Trop. Med. Parasitol. 41: 185-192.

Lorenz C., Marques T.C., Sallum M.A., Suesdek L. 2012 Morphometrical diagnosis of the malaria vectors Anopheles cruzii, An. homunculus and An. bellator. Parasit. Vectors 5: 257.

Manly B.F.J (Ed.). 2004: Multivariate Statistical Methods: A Primer. Chapman and Hall/CRC Press, Boca Raton, 224 pp.

Masmeatathip R., Ketavan C., Duvallet G. 2006: Morphological studies of Stomoxys spp. (Diptera: Muscidae) in central Thailand. Kasetsart J. (Nat.Sci.). 40: 872-881.

Morales Vargas R.E., Phumala-Morales N., Tsunoda T., Apiwathnasorn C., Dujardin J.P. 2013: The phenetic structure of Aedes albopictus. Infect. Genet. Evol. 13: 242-251.

Morales-Vargas E.R., Ya-Umphan P., Phumala-Morales N., Komalamisra N., Dujardin J.P. 2010: Climate associated size and shape changes in Aedes aegypti (Diptera: Culicidae) populations from Thailand. Infect. Genet. Evol. 10: 580-585.

Muenworn V., Duvallet G., Thainchum K., Tuntakom S., Tanasilchayakul S., Prabaripai A., Akratanakul P.,
Sukonthabhirom S., Chareonviriyaphap T. 2010: Geographic distribution of Stomoxyine flies (Diptera: Muscidae) and diurnal activity of Stomoxys calcitrans in Thailand. J. Med. Entomol. 47: 791-797.

Müller P., Pflüger V., Wittwer M., Ziegler D., ChanDre F., Simard F., Lengeler C. 2013: Identification of cryptic Anopheles mosquito species by molecular protein profiling. PLoS ONE 8: e57486.

Prudhomme J., Gunay F., Rahola N., Ouanaimi F., Guernaoui S., Boumezzough A., Banuls A.L., Sereno D., Alten B. 2012: Wing size and shape variation of Phlebotomus papatasi (Diptera: Psychodidae) populations from the south and north slopes of the Atlas Mountains in Morocco. J. Vector Ecol. 37: 137-147.

RoHLF F.J. 1990: Rotational fit (Procrustes) methods. In: F.J. Rohlf and F.L. Bookstein (Eds.), Proceedings of the Michigan Morphometrics Workshop. Number 2, Ann Arbor, Michigan. The University of Michigan Museum of Zoology, Special Publication No. 2: 227-236

Ruangsittichai J., Apiwathnasorn C., Dujardin J.P. 2011: Interspecific and sexual shape variation in the filariasis vectors Mansonia dives and Ma. bonneae. Infect. Genet. Evol. 11: 2089-2094.

Schachter-Broide J., Gürtler R.E., Kitron U., Dujardin J.P. 2009: Temporal variations of wing size and shape of Triatoma infestans (Hemiptera: Reduviidae) populations from northwestern Argentina using geometric morphometry. J. Med. Entomol. 46: 994-1000.

Sumruayphol S., Apiwathnasorn C., Ruangsittichai J., Sriwichai P., Attrapadung S., Samung Y., Dujardin J.P. 2016: DNA barcoding and wing morphometrics to distinguish three Aedes vectors in Thailand. Acta Trop. 159: 1-10.

Tumrasvin W., Shinonaga S. 1978: Studies of medically important flies in Thailand V. on 32 species belonging to the subfamilies Muscinae and Stomoxyinae including the taxonomic keys (Diptera: Muscidae). Bull. Tokyo Med. Dental. Univ. 25: 201-227.

Villegas J., Feliciangeli M.D., Dujardin J.P. 2002: Wing shape divergence between Rhodnius prolixus from Cojedes (Venezuela) and Rhodnius robustus from Merida (Venezuela). Infect. Genet. Evol. 2: 121-128.

Zumpt F (Ed.). 1973: The Stomoxyine Biting Flies of the World. Gustav Fischer Verlag, Stuttgart, 175 pp. 